\title{
An Accurate Life Estimation Method for Existing Railway Bridges
}

\author{
P. B. R. Dissanayake and S.C. Siriwardane
}

\begin{abstract}
The paper proposes an accurate methodology to estimate remaining fatigue lives of riveted railway bridges. The proposed method mainly consists of measured stress histories, recently developed sequential law and fully known Wöhler curve. Here, it is essential to use the fully known Wöhler curve as the related fatigue curve. Therefore the technique, which utilizes to transfer the partially known Wöhler curve to fully known curve, is also discussed under this paper. Since most of the bridges do not have past strain measurements, this method describes reasonably accurate procedure to obtain the past stress histories from present day measured stress histograms. Initially paper describes the proposed method for remaining fatigue life estimation. Secondly remaining fatigue life of an existing railway bridge is estimated by performing a case study. Case study describes the details of the considered railway bridge and the appraisals related to condition evaluation, FE analysis, material testing, experimental static and dynamic load testing. Then the remaining fatigue lives of each critical components of the bridge are obtained. Hence validity and merits of proposed method is confirmed by comparing the results with previous method-based fatigue lives.
\end{abstract}

Keywords: Remaining life, Railway bridge, Sequential law, Health monitoring

\section{Introduction}

In past two decades, a significant amount of efforts have been directed towards the development of structural health monitoring and non-destructive assessment methods to manage civil structures more efficiently [1]. At present, rail authorities all over the world are paying special attention to evaluate the remaining fatigue life of riveted railway bridges, since most of these bridges are nearing the end of their theoretical fatigue lives. Furthermore, the fatigue behaviour of wroughtiron and older steels, which were chiefly used for the construction of these bridges, is not well known. These observations coupled with the lack of information on loading history of these bridges raise question about their fatigue performance [2]. As a result, the assessment of remaining fatigue life of a riveted railway bridge for continuing services has become more important than ever, especially when decision making regarding structure replacement, deck replacement or other major retrofits.

Experiences from engineering practices have indicated that fatigue analysis based on specification loads and distribution factors usually underestimates the remaining fatigue life of existing bridges by overestimating the live load stress ranges. In this context fatigue evaluation based on field measured stress range histograms under actual traffic load proves to be a more accurate and efficient method for existing bridges $[3,4]$. Most of the present day fatigue assessment approaches used for railway bridges are generally based on combination of measured stress histories, Miner's rule [5] and railway code provided fatigue curve (also referred to as $S-N$ or Wöhler curve). However, the Miner's rule does not properly take account of loading sequence effect [6-8]. As a result, real fatigue life due to same loading pattern is higher than the Miner's expectation for increasing type loads and it is lower than the Miner's expectation for decreasing type loads. Recently, a new damage indicator-based sequential law [8] was originated to overcome this shortcoming of Miner's rule and it has been proved that sequential law gives more realistic results than Miner's rule when material is subjected to variable amplitude loading.

Generally, railway bridges are subjected to changes of traffic load and frequency of operations with rapid development of transportation facilities which is encountered with in the period of age. Therefore, most of the

$$
\begin{aligned}
& \text { Eng. (Dr.) P.B. R. Dissanayake, B.Sc. Eng. (Hons) (Peradeniya), C. } \\
& \text { Eng., MIE(Sri Lanka), M.Eng., Dr. Eng. (Ehime), Senior Lecturer in } \\
& \text { Civil Engineering, Department of Civil Engineering, the University of } \\
& \text { Peradeniya. } \\
& \text { S. C. Siriwardane, B.Sc. Eng. (Hons) (Peradeniya), M.Phil (Peradeniya). }
\end{aligned}
$$


railway bridges subjected to variable amplitude loadings including both increment and decrement of live load. Since the Miner's rule produces inaccurate predictions to the real failure in variable amplitude loading [6-8], it is doubtful to use the Miner's rule for remaining fatigue life estimation of railway bridges. But as for the authors view, related investigations to remove the usage of Miner's rule against the sequential law for remaining fatigue life estimation of existing railway bridges have not been so far attended.

Therefore major objective of this paper is to check the significance and applicability of the sequential law to estimate the remaining fatigue life of a riveted railway bridge by proposing a new method based on measured stress histories, recently developed sequential law [8], and Wöhler curve. Railway code provided Wöhler curve only describes stress ranges, which are corresponding to more than ten thousands of failure cycles (usually called as partially known Wöhler curve). But for the application of sequential law to estinate the fatigue life, it is compulsory to have fully known Wöhler curve. Therefore the technique, which utilizes to transfer the partially known Wöhler curve to fully known curve, is also discussed under this paper. Further this paper describes the reasonably accurate procedure to obtain the past stress histories from present day measured stress histograms. This is of extreme importance because most of the bridges do not have the past strain measurements.

Initially paper describes the proposed method for remaining fatigue life estimation. The details of case study railway bridge and the appraisals related to condition evaluation, material testing, field static and dynamic load testing, structural analysis are mentioned. Then, the remaining fatigue life of each critical component of the bridge is discussed. Finally comparisons of the results are made with Miner's rule-based previous estimation. Hence, validity and applicability of the proposed approach is discussed.

\section{Proposed method for remaining fatigue life estimation}

Proposed method for remaining fatigue life estimation of an existing riveted railway bridge is discussed in this section. Particular methodology follows three major steps such as stress evaluation, determination of Wöhler curve and application of sequential law.

\subsection{Structural appraisal and stress evaluation}

In order to apply the uniaxial sequential law, it is essential to determine the primary stress ranges generated by the passage of trains over the bridge. Therefore, it is required to know the stress cycles (stress histories) distributions of all the critical members for trains that are included in present and past timetables. Since fatigue evaluation based on field-measured stress range histograms under actual traffic loads of the bridge is a more accurate and efficient method for existing bridges $[3,4]$, this section describes the evaluation methodology of real stresses in the bridge related to the current state.

Initially a condition survey has to be carried out to assess the present geometric condition and damages. Generally, it consists of detailed visual examination, in-situ measurements of each component of the bridge and non-destructive field examinations. Then laboratory tests will need to be carried out to determine the current state of mechanical properties and chemical composition of the bridge materials. The static and dynamic load testing can be recommended as next major step to study the real behavior of the bridge under various load combinations. The obtained results is used to develop a proper analytical model and further assists in evaluating actual dynamic factors of each structural component. Finally the bridge will be subjected to finite element (FE) analysis under test and actual loadings to determine stresses and deflections, as well as variations of stresses under moving loads. Material properties which are obtained through laboratory tests and current geometric properties obtained from condition assessment are applied to the $\mathrm{FE}$ model for more realistic outputs. The validation of the FE model has to be carried out by comparing the results from analysis with those from field-tests. The FE model, which gives better comparison to load test results can be nominated as "validated analytical model". Hence, a validated analytical model is used to obtain past and present static stress histories due to passage of trains specified by the owner. 
Due to the dynamic effect of moving trains, the actual working stresses should be higher than the analytical static stress. Therefore, the dynamic factors of each member, which are found experimentally, is used to multiply the static stress to get the service stresses. Finally, the stress histories have to be converted into stress ranges by using the reservoir counting method (BS 5400 part 10,1980). The described stress evaluation procedure is briefly summarized as shown in Fig. 1.

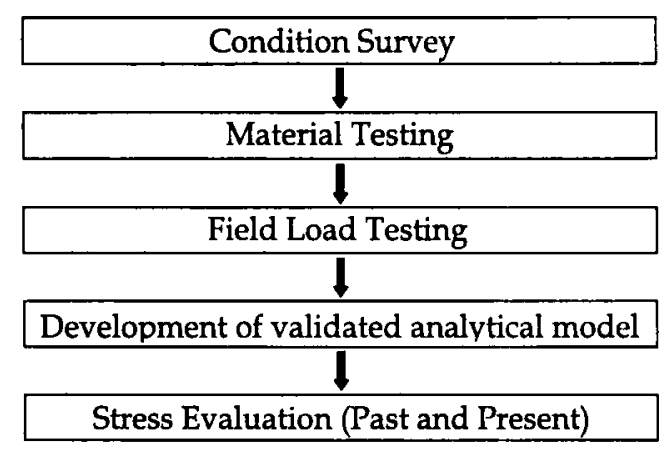

Figure 1. Flow of stress evaluation procedure

\subsection{Determination of Wöhler curve}

To capture the fatigue damage due to the secondary stresses near the riveted connection or discontinuities, detail class [9] of riveted connection based Wöhler curves are considered for life estimation. The detail class is determined by considering the quality of the workmanship and current condition of the riveted connection. Generally, the $S-N$ curve, which is mentioned under the UK railway assessment code [10], is considered as the suitable fatigue curve for this evaluation. But, chosen fatigue curve only describes stress ranges, which are corresponding to more than ten thousands of failure cycles (usually called as partially known Wöhler curve). In the case of sequential law it is essential to know the Wöhler curve for full range of the number of cycles. Therefore, the chosen partially known Wöhler curve, which is mentioned under the UK railway assessment code [10], has to be transferred to fully known Wöhler curve by using Kohout and Vechet Wöhler curve modeling technique [11].

\subsection{Application of sequential law}

A new damage indicator based sequential law in multiaxial fatigue ${ }^{8}$ ), is used to obtain a more realistic fatigue life for the bridge. A detailed description of the sequential law is available in the corresponding paper [8]. Here only the concept is summarized with an algorithm for understanding (see Fig. 2).

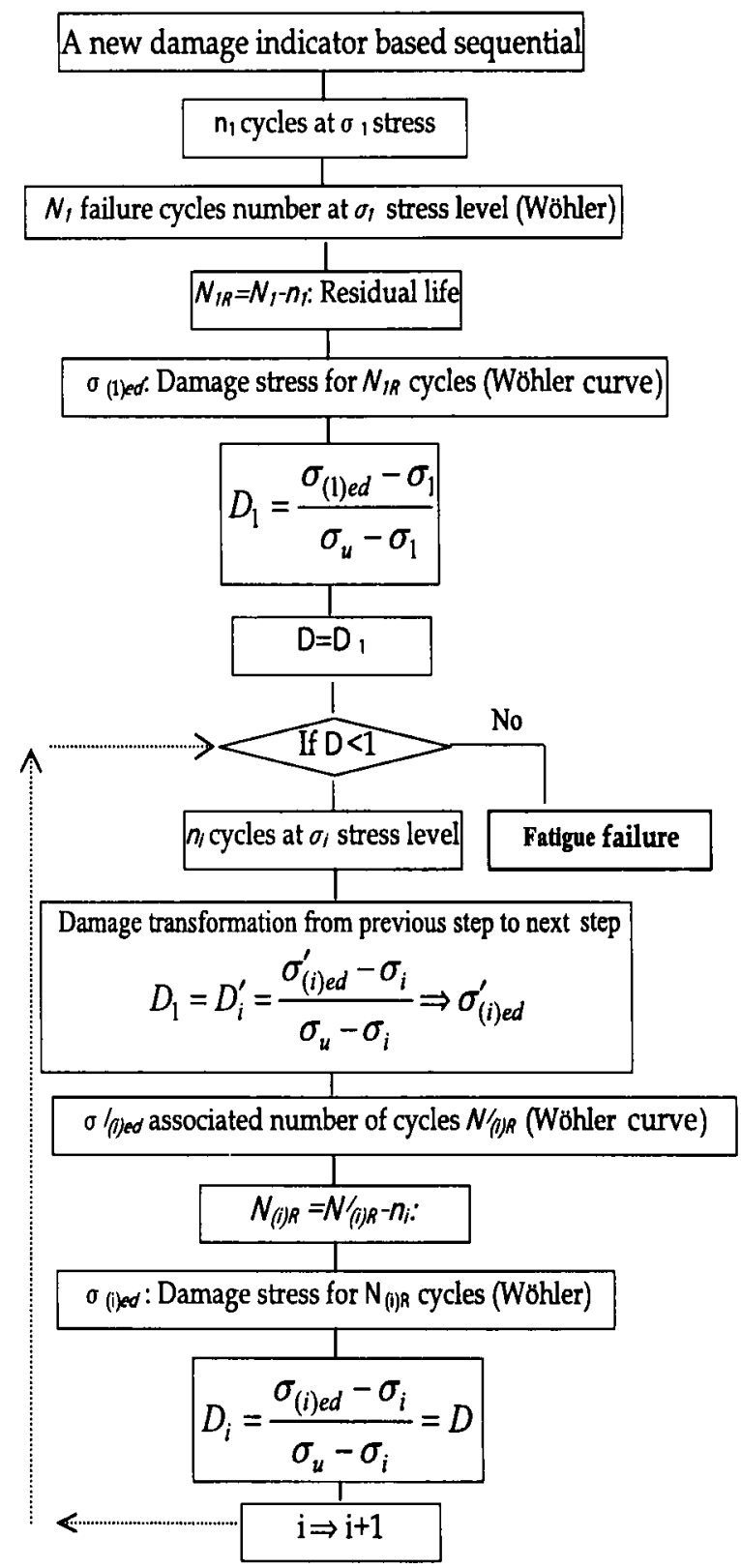

Figure 2. Flow chart for damage stress based sequential law

The hypothesis behind the model is that if the physical state of damage is the same, then fatigue life depends only on loading condition. Therefore, the life can be assessed using the Wöhler curve for new structures, which are still free of damage. At load level $i$, a certain stress amplitude $\sigma_{i}$ is applied for a number of cycles $n_{i}$ Here the number of cycles to failure from the Wöhler curve for $\sigma_{i}$ is $N_{i}$. Thus, after $n_{i}$ applied cycles, the residual life is considered as $\left(N_{i}-n_{i}\right)$ for load level $i$. From the Wöhler curve, $\sigma_{(i) d e}$ is 


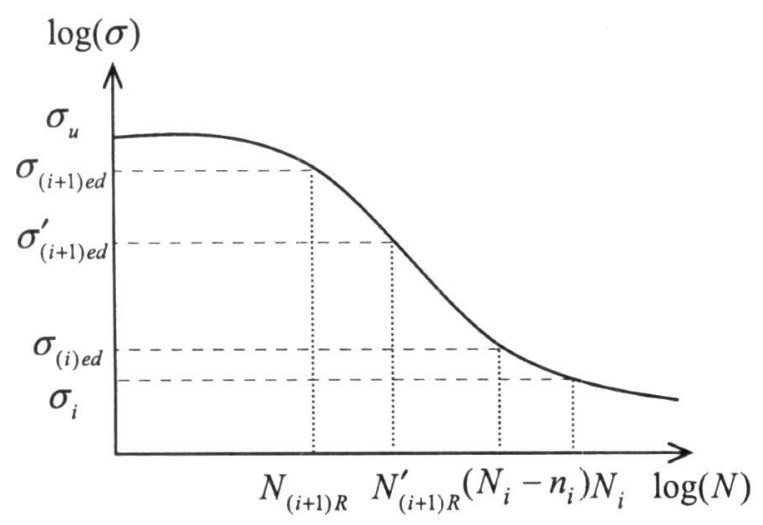

Figure 3. Schematic representation of parameters in Wöhler curve

said to be $i^{\text {th }}$ level damage stress (otherwise can be introduced as stress relevant to the residual life) which corresponds to the failure life (Ni-ni), (see Fig. 3). Hence, the damage stress, Di is defined as,

$D_{i}=\frac{\sigma_{(i) e d}-\sigma_{i}}{\sigma_{u}-\sigma_{i}}$

where $\sigma_{u}$ is the magnitude of ultimate stress. The stress field can be considered in terms of equivalent von Mises stress and in this way the model can be applied to the multiaxial fatigue. In the case of uniaxial loading condition, the stress field can be considered in terms of corresponding stress values. The $\sigma_{(i) e d}$ is equal to $\sigma_{1}$ at first cycle when damage indicator $D_{i}=0$ and $\sigma_{\text {(i)ed }}$ is equal to $\sigma_{u}$ at the last cycle when $D_{i}=1$. Therefore, the damage indicator is normalized to 1 at the failure of material.

Same damage is then transformed to load level $i+1$ and hence damage equivalent stress at level $i+1$ is calculated with the relation,

$D_{i}=\frac{\sigma_{(i) e d}-\sigma_{i}}{\sigma_{u}-\sigma_{i}}=\frac{\sigma_{(i+1) e d}^{\prime}-\sigma_{i+1}}{\sigma_{u}-\sigma_{i+1}}$

Further simplification of Eq. (2), $\sigma_{(i+1) e d}^{\prime}=D_{i}\left(\sigma_{u}-\sigma_{i+1}\right)+\sigma_{i+1}$

where $\sigma_{(i+1) e d}^{\prime}$ is damage equivalent stress at the level $i+1$. Thus, the corresponding equivalent number of cycles to failure, $N_{(i+1) R}$ can be obtained from the Wöhler curve as shown in Fig. 3. The $\sigma^{\prime}{ }_{i+1}$ is the magnitude of applied stress and it is subjected to $n_{i+1}$ number of cycles at the level $i+1$. Then the corresponding residual life at the load level $i+1, N_{(i+1) R}^{\prime}$ is calculated as,

$N_{(i+1) R}=N_{(i+1) R}^{\prime}-n_{(i+1)}$

Hence the damage stress $\sigma_{(i+1) e d}$ which corresponds to $N_{(i+1) R}$ at loading level $i+1$, can be obtained from the Wöhler curve as shown in Fig. 3. Then the cumulative damage at loading level $i+1$ is defined as,

$D_{(i+1)}=\frac{\sigma_{(i+1) e d}-\sigma_{i+1}}{\sigma_{u}-\sigma_{i+1}}$

The same procedure is followed until the failure of material, that is, when damage indicator $D_{i}=1$.

\section{Case study: Remaining life estimation of a riveted railway bridge}

The selected bridge to evaluate the remaining fatigue life is one of the longest railway bridges in Sri Lanka having a length of $160 \mathrm{~m}$ (Fig.4). It is a six span riveted bridge with double lane rail tracks having warren type semi through trusses, supported on cylindrical piers. The bridge deck is made of wrought iron and the piers are made of cast iron casings with infilled concrete. The bridge has constructed in 1885. Details of trains carried by the bridge at present and their frequencies illustrate that the bridge is subjected to variable amplitude loading.
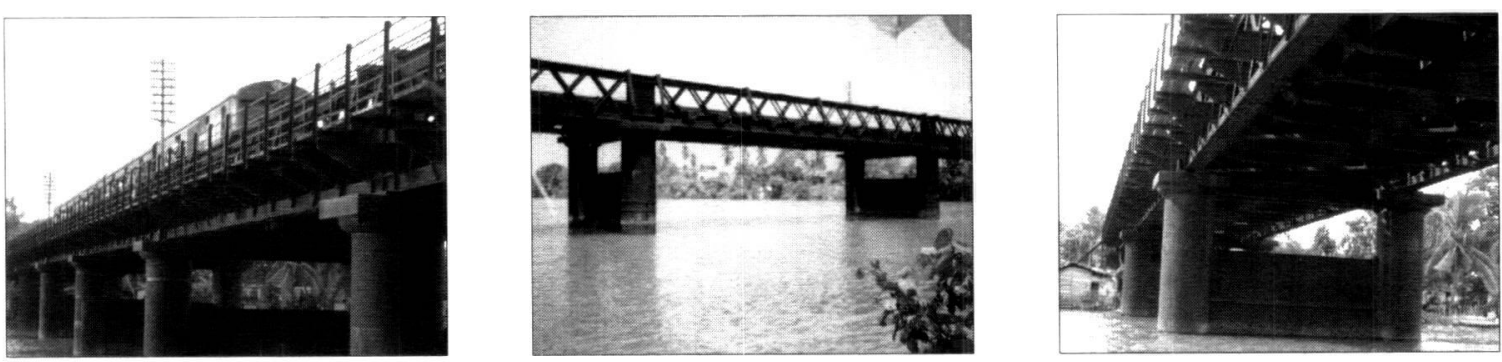

Figure 4. General views of the riveted bridge 

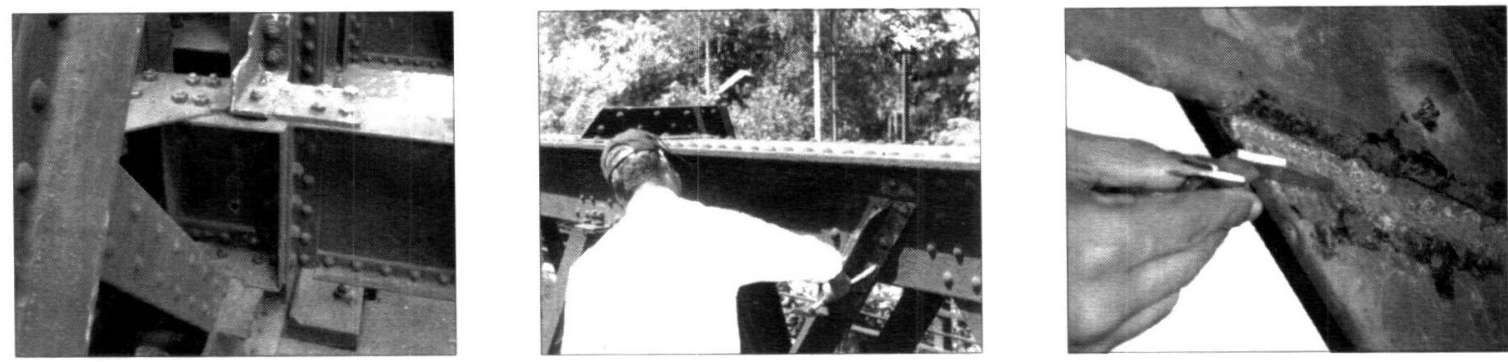

Figure 5. Some of photos to show the corrosion of the bridge

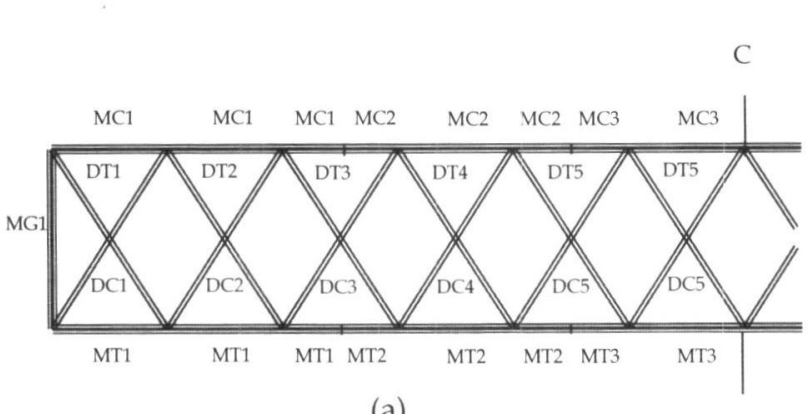

(a)

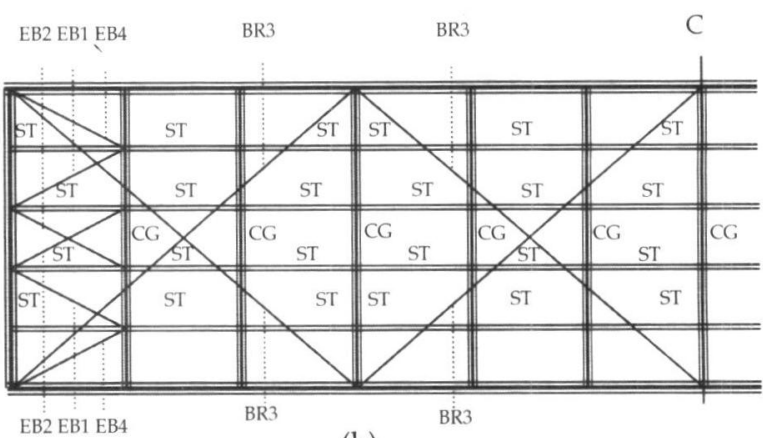

(b)

Figure 6. Member set categorization (a) Main truss girder (b) Horizontal bridge deck

\subsection{Structural appraisal and stress evaluation}

Extensive condition survey, laboratory testing, field-testing, and analytical work were performed to obtain more realistic stresses of critical components of the bridge $[12,13]$.

\subsubsection{Condition survey}

The condition survey revealed that some places of the bridge have been subjected to mild corrosion due to the absence of anti corrosive coating (see Fig.5). No visual cracks were observed in any component of the super structure. In situ measurements of member sizes, connections and support bearings verified the fact that the existing drawings were applicable and only few significant variations were observed. Further the bridge components have been categorized to several groups entitled "member set" by considering similar cross sectional properties as shown in Fig.6. Finally it can be said that comparative maintenance work carried out on the bridge thus far is satisfactory.

\subsubsection{Material testing}

The sampling of materials, specimen preparation and testing were carried out according to the ASTM standards. The chemical analyses as well as microscopic examinations led to conclusion that the bridge super structure material is wrought iron. A summary of the
Table 1: Mechanical properties of super structure material

\begin{tabular}{|l|l|}
\hline Property & Values \\
\hline Density & $7600 \mathrm{~kg} / \mathrm{m}^{3}$ \\
Yield Strength in tension & $240 \mathrm{MPa}$ \\
Ultimate tensile strength & $383 \mathrm{MPa}$ \\
Elastic modulus & $195 \mathrm{GPa}$ \\
Fatigue limit & $155 \mathrm{MPa}$ \\
\hline
\end{tabular}

obtained mechanical properties of the wrought iron is shown in Table 1.

\subsubsection{Field load testing}

Static and dynamic load testings were performed to study the real behavior of the bridge under various load combinations. The in situ measurements were performed using two M8 engines, each weighting $1120 \mathrm{kN}$, which is the heaviest rail traffic in current operation. The bridge was instrumented with strain gauges placed at selected locations to measure normal strains. In addition, the triaxial vibrations were recorded at several locations using accelerometers. In order to measure free vibration, accelerations were recorded after the M8 engines had crossed the bridge. Displacement transducers were used to measures vertical deflection at three places around the mid span area of the bridge. 


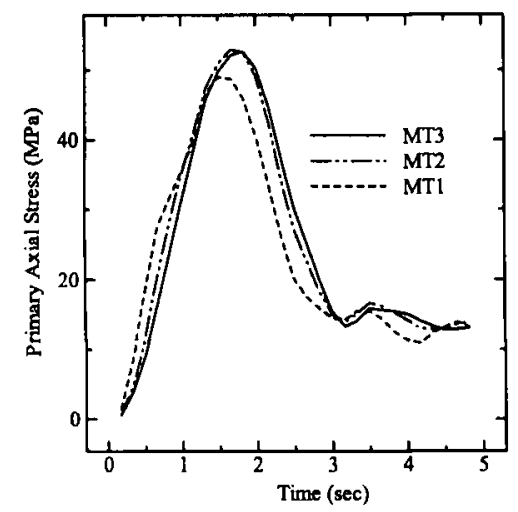

(a)

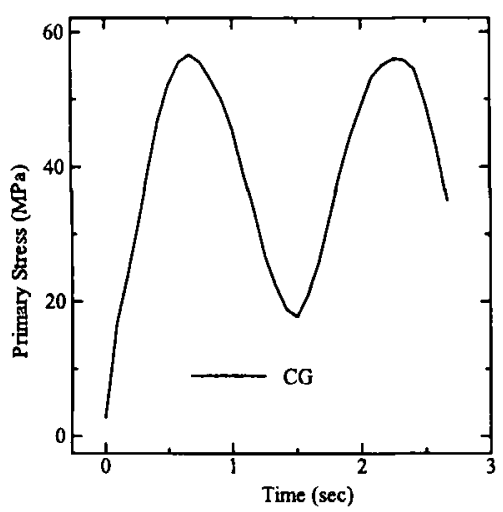

(d)

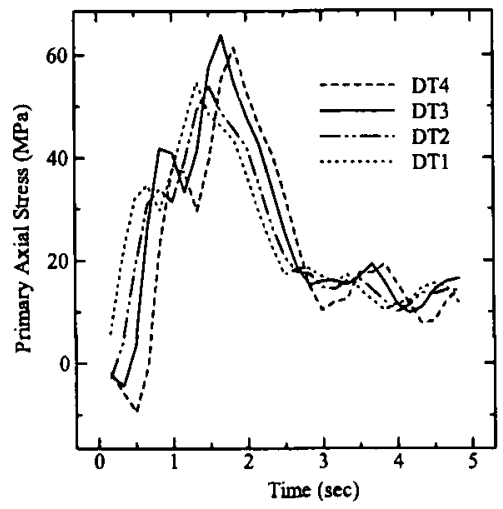

(b)

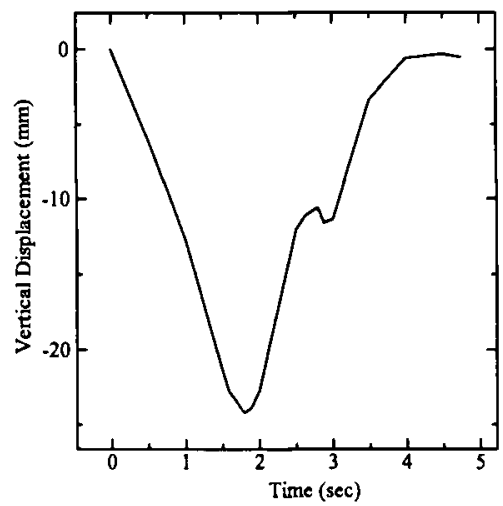

(e)

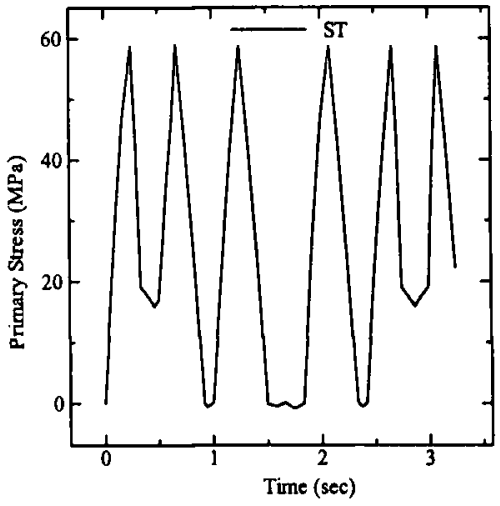

(c)

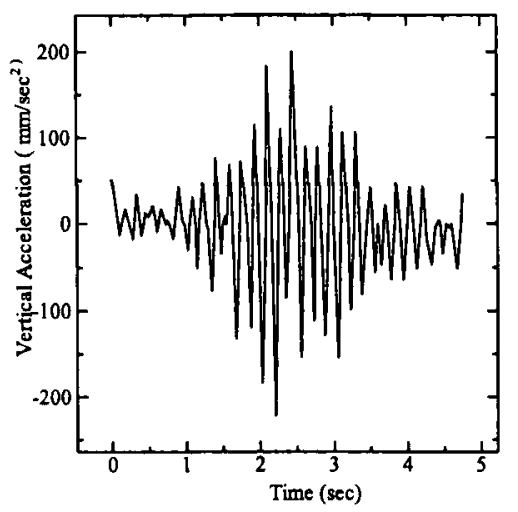

(f)

Figure 7. Field measurements of the bridge due to heaviest load (a) Stresses at bottom chord of the main girder (b) Stresses at diagonal members which are usually subjecetd to tensile stress (c) Stresses at stringers (d) Stresses at secondry cross girders (e) Vertical displacernnt at midspan ( $f$ ) Vertical acceleration at midspan.

To acquire static and dynamic responses of strains, displacements and accelerations, sophisticated static and dynamic data loggers were used. To obtain the different type of load combinations, which are critical to the bridge, the two test-engines were placed as well as moved under different speeds. The considered three static load combinations are defined as static load case (SLC) 1,2 and 3 by considering criteria of maximum shear effect, maximum bending effect (maximum deflection) and maximum torsion effect to the bridge deck respectively. The criteria, which were considered for dynamic load combinations, basically illustrate that impact effect to the bridge with different levels of speed and traction force effect. Apart from the above mentioned formal field load testing, the bridge was subjected to a two days continuous field measurement program under present day actual traffic. Even though under this investigation many types of load combinations were considered, only the combinations, which were used to evaluate the fatigue life of the bridge, are shown in this paper. When the bridge is affected by maximum load due to the present day heaviest train passage, the obtained sample measurements are shown in Fig. 7. Maximum values of responses which were measured while moving the test-engine with different speeds, are plotted against the speed of the train (Some of plots are illustrated in Fig. 8). Finally the dynamic factors were obtained as 1.3, 1.4 and 1.4 for main truss girders, secondary cross girders by the ratio of maximum dynamic response to static response.

\subsubsection{Development of validated analytical model}

The Bridge girder was analyzed using the finite element (FE) method employing the generalpurpose package SAP 2000. A threedimensional (3D) model (Fig. 9) of one complete middle span of the bridge was analyzed under test loadings and actual loadings to determine stresses in members and deflections, as well as variations of stresses under moving loads. The 




(a)



(b)

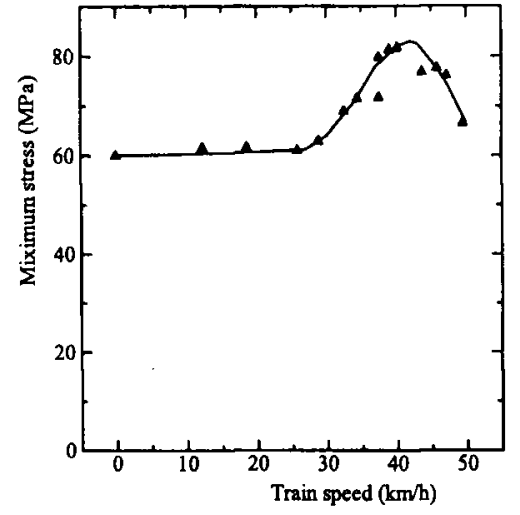

(c)

Fig. 8. Dynamic factor determination curves (Maximum responds variation with speed) (a) Main truss girder (b) Secondary cross girders (c) Stringers
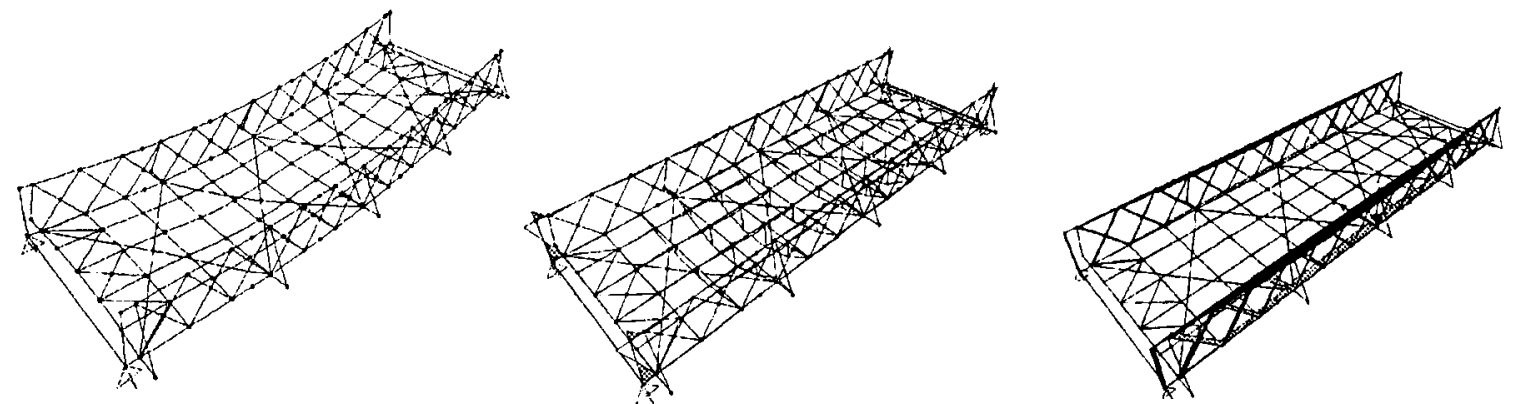

Figure 9. 3D frame element model for single span

(a) Deflected shape for SLC 2 (b) Axial force diagram at SLC 2 (c) Bending moment diagram at SLC 2

bridge deck was modeled with 3D frame elements and the riveted connections are assumed to be fully-fixed [2]. Even though the cross girders are ideally supported on bottom chord of the main truss girder, the assumption of rotational stiffness behavior with small magnitude for representative connection of cross girder to truss were found to be in better agreement with field measurements than the pinned connection assumption. Every riveted connections of cross girders with both stringers and bracings were assumed to be fixed.

The validation of FE model was carried out by comparing the results from analysis with those from field-tests as shown in Table 2. From the results of static load cases it was seen that there is a good agreement among analytical results of the FE model and the measurement of the actual bridge. Therefore, the considered 3D frame element model was defined as ivalidated analytical model.

\subsubsection{Stress evaluation}

Since the types of trains used are changed with age of the bridge, the age had to be divided in to several periods. According to the past and present timetables of the bridge, it could be assumed that the traffic sequence is almost constant during a single week of each period of age. Then the validated analytical model was used to obtain the static stress histories of each critical member during a single week of each period. Due to the dynamic effect of moving trains, the actual working stresses should be higher than the analytical static stress. Therefore, the dynamic factor of each member, which was found experimentally, was used to multiply the static stress to get the service stresses. Then the stress histories were converted into stress ranges by using the reservoir counting method [9].

\subsection{Determination of Wöhler curve}

Field investigations reveal that the riveted connections of the bridge represent lapped or spliced connection behavior with normal clamping force. Therefore, riveted connections were classified as class Wrought-iron (WI), which is proposed by the UK railway assessment code [10]. Hence the S-N curve, which is mentioned under the UK railway 
Table 2. Comparison of FE analytical results with load test results

\begin{tabular}{|c|c|c|c|c|c|c|}
\hline \multirow[t]{2}{*}{ Static load case } & \multicolumn{3}{|c|}{ Displacement (mm) } & \multicolumn{3}{|c|}{ Stress (MPa) } \\
\hline & Location of measurement & Load test & FEM & Location of measurement & Load test & FEM \\
\hline SLC 1 & Main girder mid span & 19.4 & 21.0 & $\begin{array}{l}\text { Critical member of DC3 } \\
\text { Critical member of DT3 } \\
\text { Critical member of MT3 }\end{array}$ & $\begin{array}{r}-40.2 \\
51.4 \\
47.3\end{array}$ & $\begin{array}{r}-40.6 \\
57.3 \\
48.2\end{array}$ \\
\hline SLC 2 & Main girder mid span & 21.3 & 22.5 & $\begin{array}{l}\text { Critical member of DC3 } \\
\text { Critical member of DT3 } \\
\text { Critical member of MT3 }\end{array}$ & $\begin{array}{r}-37.8 \\
44.5 \\
53.5\end{array}$ & $\begin{array}{r}-37.7 \\
43.6 \\
53.9\end{array}$ \\
\hline SLC 3 & Main girder mid span & - & 19.1 & $\begin{array}{l}\text { Critical member of DC3 } \\
\text { Critical member of DT3 } \\
\text { Critical member of MT3 }\end{array}$ & $\begin{array}{r}-39.5 \\
35.2 \\
39.0\end{array}$ & $\begin{array}{r}-39.9 \\
41.5 \\
44.7\end{array}$ \\
\hline
\end{tabular}

assessment code for WI detail class connection [10], was transferred to fully known Wöhler curve by using Kohout and Vechet Wöhler curve modeling technique [11]. The obtained function and the geometrical shape of new fatigue curve, which corresponds to class WI riveted connection, are illustrated in Fig.10.

\subsection{Application of sequential law}

The new damage indicator (present $\mathrm{Di}$ value) was calculated from the date of bridge construction to the present by considering the sequence of stress ranges of each critical member. Assuming that future sequence of passage is similar to that of the present day, the time taken to reach the present day's $D_{i}$ values to one (when $D_{i}=1$ is considered as fatigue failure) was considered as the remaining fatigue life for each critical member. The calculated remaining fatigue lives for critical members of each member set are shown in Table 3. The critical members of which the stress range is entirely in compression zone, the effect of fatigue damage were ignored [9].

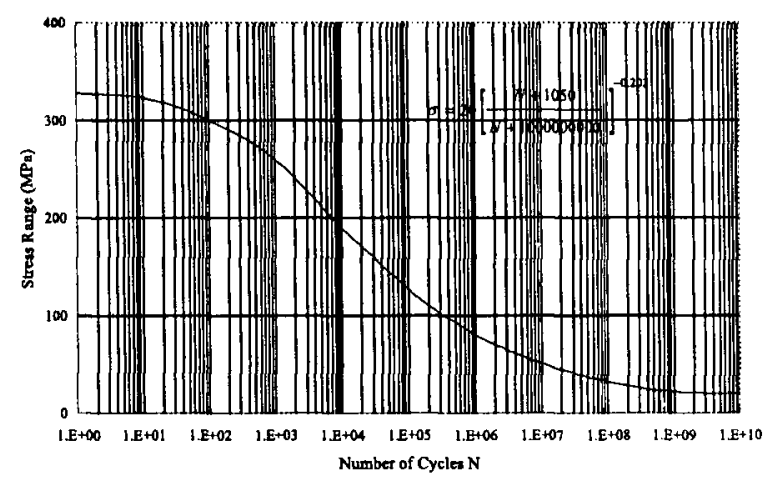

Figure 10. Predicted Wöhler curve for wrought iron material

\section{Comparisons of remaining fatigue lives}

Obtained remaining fatigue lives for the critical members of each member sets were compared with the Minerís rule-based estimations (previously used method) as shown in Table 3. Even though the predicted lives from the two approaches illustrates some amount of deviation from each other, it can be said that both approaches have highlighted that the cross girders becomes the most critical members to fatigue failure. Further it reveals that in the case of truss members of main girder, the sequential law-based remaining fatigue life gives higher values than Minerís rule-based values. However, it is the opposite for bridge deck members. Since Minerís rule estimation produces pessimistic results with increase of loads and optimistic results with decreases loads [8], it can be said that in case of truss members, the global increment of live load of trains with each period of age has greater effect on fatigue damage than local variation (increase and decrease of loading during a week) of loading in each week. Similarly, it can be seen that in the case of bridge deck members (cross girders, stringers and bracings), the local variation of loading has a greater effect on fatigue damage than global increment of loading. Although these types of conclusions are particular to this type of a bridge and fatigue criticality of structure could vary from bridge to bridge.

\section{Conclusions}

Condition evaluation of the bridge exhibits that the overall maintenance of the considered bridge is satisfactory. However, there are localized mild corrosion at few places, and these 
Table 3. Summary of remaining fatigue lives for critical members in member sets

\begin{tabular}{|l|c|c|c|}
\hline \multicolumn{1}{|c|}{ Bridge component } & Member set & \multicolumn{2}{c|}{ Remaining Fatigue life from today (years) } \\
\cline { 2 - 4 } & & Miner's Rule & Sequential Law \\
\hline Main girder bottom chord & MT1 & 305 & 323 \\
Main girder bottom chord & MT2 & 156 & 165 \\
Main girder bottom chord & MT3 & 157 & 169 \\
Cross girders & CG & 20 & 12 \\
Stringers & ST & 24 & 13 \\
Truss diagonal (tension member) & DT1 & 179 & 191 \\
Truss diagonal (tension member) & DT2 & 168 & 171 \\
Truss diagonal (tension member) & DT3 & 131 & 138 \\
Truss diagonal (tension member) & DT4 & 152 & 162 \\
\hline
\end{tabular}

need immediate attention. It is found that, the lowest remaining life due to fatigue for a member is 12 years, under current loadings, speeds and frequencies. Thus, it may be concluded that the bridge deck can be used for another 12 years provided that the speed, frequency, and weight of the trains are not increased. If proper maintenance work is carried out and the critical members are replaced with new members with longer life, the bridge will be able to provide further service.

Comparison of Miner's estimations and sequential law predictions (the proposed method) illustrates considerable amount of deviation of remaining lives. This deviation and the phenomelogical validity of the new damage indicator-based sequential law tend to conclude that the application of Miner's rule-based previous approach is not much advisable for the evaluation of remaining fatigue life of riveted railway bridges in future and proposed method is recommended for general application. The obtained function and the geometrical shape of the fully known Wöhler curve, which corresponds to normal or intermediate effect of clamping force at riveted connections, can be employed to assess the fatigue damages of other wrought iron riveted bridges.

Since this investigation has not been captured the effect of various types of micro structural changes at highly stressed locations, comparisons of above approach with microsopic level fatigue theories are currently underway.

\section{Acknowledgement}

The authors wish to express their sincere gratitude to Senior Professor M.P Ranaweera and other team of experts who work in the Sri Lankan Railway Bridge project. The kind support given by the Sri Lanka Railways (SLR) is also appreciated.

\section{References}

1. Sherif, B., Shuichi, M. and Toshiyuki, O., Nondestructive damage detection scheme for steel bridges, Joumal of Applied Mechanics, JSCE, Vol.9, pp. 63-74, 2006.

2. Imam, B., Righiniotis, T.D. and Chryssanthopoulos, M. K., Fatigue Assessment of Riveted Railway Bridges. International Journal of Steel Structures, KSSC, Vol.5 (5), pp. 485-494, 2005.

3. Köröndi, L., Szittner, A., Kállo, M. and Krisróf, L., Determination of fatigue safety and remaining fatigue life on a riveted railway bridge by measurement. Journal of Constructional Steel Research, Elsevier, paper number 327, Vol. 46 (1-3), pp. 430, 1998.

4. Constantine, C.S., Ioannis, G.R. and John, Ch. E., Condition assessment and retrofit of historic steel-truss railway bridges. Journal of Constructional Steel Research, Elsevier, Vol. 60 (8), pp. 1213-1225, 2004.

5. Miner, M.A., Cumulative Damage in Fatigue. Journal of Applied Mechanics, ASME, Vol.12 (3), pp. 159-164, 1945.

6. Suresh, S., Fatigue of materials. Second edition, Cambridge University Press, UK, 1998.

7. Dattoma, V., Giancane, S., Nobile, R. and Panella F.W., Fatigue life prediction under variable loading based on a new non-linear continuum damage mechanics model. International Journal of Fatigue, Elsevier, Vol. 28 (2), pp. 89-95, 2006.

8. Mesmacque, G., Garcia, S., Amrouche, A. and Rubio-Gonzalez, C., Sequential law in multiaxial fatigue, a new damage indicator. International Journal of Fatigue, Elsevier, Vol. 27 (4), pp. 461-467, 2005.

9. BS 5400, Part 10, Code of practice for fatigue, Steel Concrete and Composite Bridges. British Standard Institutions.1980.

10. Network Rail, Rail track Line Code of Practice. The Structural Assessment of Underbridges, RT/ CE/C/025, Rail track, 2001. 
11. Kohout, J. and Vechet, S., A new Function for Fatigue Curves Characterization and Its Multiple Merits. International Journal of Fatigue, Elsevier, Vol. 23 (2), pp. 175-183, 2001.

12. Ranaweera, M.P.R., Aberuwan, H., Mauroof, A.L.M., Herath, K.R.B., Dissanayake, P.B.R., Siriwardane S.A.S.C. and Adasooriya, A.M.N.D., Structural appraisal of railway bridge at colombo over kelani river, EDC, University of Peradeniya, Sri Lanka, 2002.

13. Siriwardane, S.A.S.C., Fatigue life prediction of existing railway bridges, MPhil Thesis, University of Peradeniya, Sri Lanka, 2004. 